\title{
Geographical variations in rates of ophthalmic surgery
}

\author{
Helen S Jones, John M Yates, Peter Spurgeon, Alistair R Fielder
}

\begin{abstract}
Aims/background-Geographical variations in health care are common. There is, however, no simple explanation for why they arise. Variations in rates of ophthalmic surgery in the population aged 65 and over were investigated, with the aim of determining their cause.
\end{abstract}

Methods-Routine data sources were used to obtain the 1991-2 age and sex standardised rates for English health districts with an ophthalmic unit. Weighted least squares regression was used to study the relation between these rates and various factors describing the population and the provision of care.

Results-Surgery rates varied more than threefold. High rates of surgery were associated with high throughput and bed numbers (both $\mathbf{p}<\mathbf{0 . 0 0 1}$ ), high proportions of day case surgery $(p<0.001)$, long waiting lists ( $p<0.001)$, and a high number of theatre sessions $(p=0.002)$. Conversely, a high percentage of emergency admissions was associated with lower rates of surgery $(p=0.004)$. These six variables accounted for $58 \%$ of the variation.

Conclusion-Geographical variations were found to exist, less than two thirds being explained by differences in the provision of care. The remaining variation may partly be attributed to private practice and the lack of consensus for many ophthalmic procedures (the 'surgical signature'), including a lowering of the threshold for surgery. These findings have implications for the planning of ophthalmic services.

(Br f Ophthalmol 1996;80:784-788)

University of Birmingham, Health Services Management Centre

J M Yates

P Spurgeon

Correspondence to: Alistair R Fielder, Academic Unit Western Eye Hospital, Imperial College School of Medicine at St Mary's, Marylebone Road, London NW1 5 YE.

Accepted for publication 24 May 1996 tries were first demonstrated over 50 years ago when Glover reported large variations between areas of England in tonsillectomy rates. ${ }^{6}$ Since then, variations between small areas within one country have further been exhibited for tonsil- lectomy as well as for other procedures including hysterectomy, prostatectomy, and cholecystectomy. ${ }^{4-10}$ Ophthalmology is no exception to this with variations being demonstrated for the specialty as a whole, ${ }^{12}$ as well as for specific procedures such as cataract extraction. ${ }^{4} 9$ 11-13

Although the literature in this area is expanding rapidly there is still no simple explanation for why differences in rates occur. Do they simply reflect differing need in the population or do low rates indicate underprovision or alternatively do high rates indicate inappropriate care? Variations have been attributed to differences in a combination of factors including: age and sex distributions; disease incidence; random variation; service availability (for example, beds, staffing); clinical judgment; patient demand; previous years' rates; custom; omission of private cases; coding differences; or data inaccuracies. ${ }^{4}$ Although it is unlikely that factors such as morbidity differences will have a large effect when comparing, for example, small areas within one region or country, no clear consensus exists on the relative importance of many of these factors.

Many ophthalmic disorders, such as cataract, affect primarily the elderly population. With ever increasing life expectancy the number of people requiring ophthalmic surgery will rise, increasing the pressure on this specialty. There is, therefore, a real need to assess the extent of variations in admission rates for ophthalmic surgery and to determine which are the important factors in this.

This study used routinely available data to investigate the extent, and possible causes, of variations in ophthalmic surgery rates in English district health authorities, for the population aged 65 years and over. Although previous studies have looked at ophthalmology, these have been mainly directed towards international comparisons ${ }^{12}$ where variations are likely to be due to different factors, such as major policy or organisational differences. In addition, since these studies were published, ophthalmic surgery has undergone several major advances - for example, the establishment of day case surgery as a safe and recommended option for certain procedures and the introduction of new surgical techniques (such 
as the change from intracapsular to extracapsular cataract extraction and, more recently, phakoemulsification).

\section{Methods}

Data for the period April 1991 to March 1992 were obtained from the Health Service Indicators (HSI) database produced by the Department of Health and from a database created by the Inter-Authority Comparisons and Consultancy (IACC) group based at the University of Birmingham. These databases provided information on the rates of surgery in each English district health authority together with population characteristics and various indicators of health service provision and efficiency such as bed numbers and waiting times.

We investigated the variation between districts in the ophthalmology surgery rate per 1000 district residents aged $\geqslant 65$ years treated anywhere. These rates were already age and sex standardised in HSI by reference to 1991 England age and sex profiles, thus removing the potentially confounding effect of these two variables. We studied the relation between these rates and 29 possible causative factors describing the provision of care and population demography (Table 1). Before analysis the normality of the data was assessed using histograms and normal probability plots and non-normal data transformed as necessary. Gross outliers suspected of being inaccurate were excluded. Correlation coefficients were calculated between rates and explanatory factors. Factors found to be significantly correlated with the ophthalmic surgery rates at the 0.05 level were entered into a stepwise weighted least squares regression model. ${ }^{14}$ Such a model enables assessment of the independent effect of each factor, adjusting for the other factors. At each stage of the model fitting variables were included if they significantly altered the model and were removed if they did not.

To ensure that 1991-2 was a representative year, the values and relative rankings of district rates and explanatory variables were compared with those for previous years using histograms and time series plots.

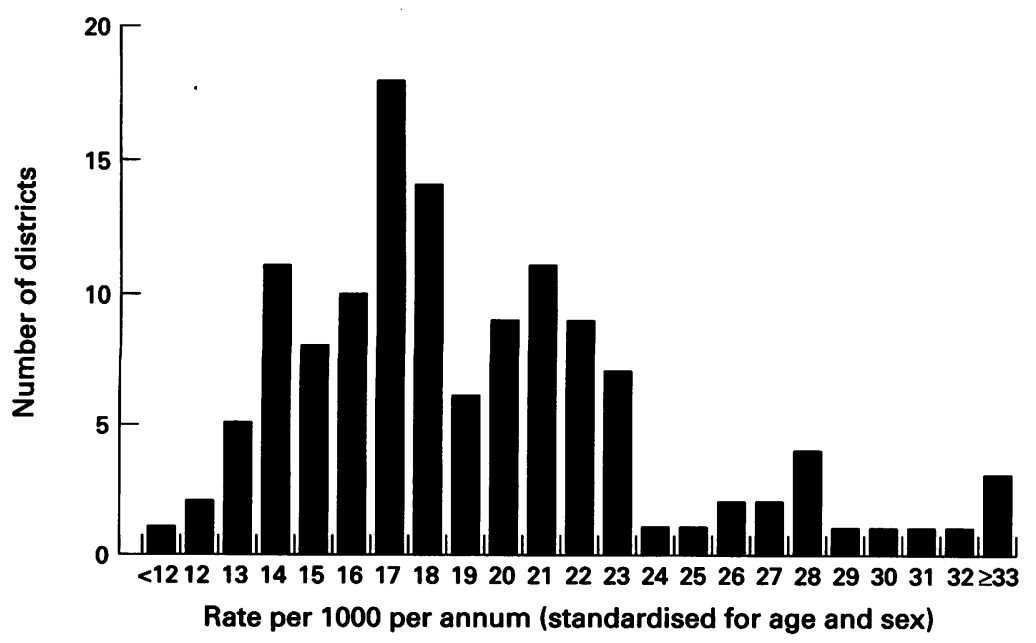

Figure 1 Age and sex standardised rates of ophthalmic surgery in 1991-2 for residents (aged $\geqslant 65$ years) of 135 district health authorities with an inpatient ophthalmic unit.
Table 1 List of 29 variables investigated for effect on rates of ophthalmic surgery

Consultants per catchment population

Senior doctors per catchment population

Unit size

Beds per catchment population

Beds per resident population

Percentage bed emptiness

Available beds per consultant

Theatre sessions per bed

Theatre sessions per catchment population

Theatre sessions per consultant

Cases per theatre session

Percentage of day cases

Percentage of emergency admissions

Waiting list per catchment population

Waiting list per consultant

Percentage waiting over 6 month

Percentage waiting over 1 year

Throughput

Turnover interval

Length of stay

New outpatients per catchment p opulation

New outpatients per consultant

Old outpatients per senior doctor

Percentage of new outpatients

Total outpatients per catchment population

Outpatient demand ratio

Jarman Underprivileged Area Score

Percentage of ethnic minorities

Net patient flow (catchment population/resident population)

\section{Results}

From a total of 184 districts in existence in 1991-2, 36 districts without an ophthalmic unit and 13 districts with very sparse data or missing rates of surgery were excluded. Also excluded was the special health authority of Moorfields Eye Hospital, London which receives patients from a large geographical area. Thus, 135 districts with an inpatient unit were analysed. The rates of ophthalmic surgery for district residents aged 65 and over ranged from 11.6 to 39.8 per 1000 per annum (Fig 1) with a mean of 19.9 (SD 5.2). Similar rates were found for the residents of districts without an ophthalmic unit.

One variable (the percentage of ethnic minorities) was logarithmically transformed before analysis in order to normalise the data. In addition, between one and three outliers were excluded from the following variables before analysis: throughput, beds per resident population, theatre sessions per consultant and per bed, consultants and senior doctors per catchment population, new and total outpatients per catchment population, and net patient flow. Thus, for the univariate analysis, the number of districts actually analysed varied between 132 and 135 depending on the variable. Ten variables were found to be significantly associated with the surgery rates using correlation coefficients (Table 2 ).

For the regression analysis seven districts had to be excluded because of missing data for one or more of the explanatory variables. Thus, the final number of districts analysed was 128 . When the 10 variables univariately associated with the rates were entered into the model six of them were found to have a significant and independent effect (Table 3). These six variables jointly explained $58 \%$ of the variation in the rates and examination of residuals confirmed that the model adequately fitted the data. 
Table 2 Variables significantly correlated with rates of ophthalmic surgery (univariate analysis)

\begin{tabular}{lrc}
\hline Variable & $r$ & $p$ Value \\
\hline Percentage of day cases & 0.60 & $<0.001$ \\
Length of stay & -0.48 & $<0.001$ \\
Throughput & 0.40 & $<0.001$ \\
Percentage of emergency admissions & -0.34 & $<0.001$ \\
Waiting list per catchment population & 0.31 & $<0.001$ \\
Waiting list per consultant & 0.30 & 0.001 \\
Theatre sessions per consultant & 0.27 & 0.002 \\
Beds per resident population & 0.21 & 0.02 \\
Theatre sessions per catchment population & 0.18 & 0.03 \\
Turnover interval & -0.17 & 0.05 \\
\hline
\end{tabular}

Table 3 Variables significantly and independently associated with rates of ophthalmic surgery (weighted least squares regression)

\begin{tabular}{lcc}
\hline & $\begin{array}{l}\text { Variation } \\
\text { explained }\end{array}$ & \\
Variable & $(\%)$ & p Value \\
\hline Throughput & 16 & $<0.001$ \\
Bed per resident population & 14 & $<0.001$ \\
Percentage of day cases & 9 & $<0.001$ \\
Waiting list per consultant & 8 & $<0.001$ \\
Percentage of emergency admissions & 7 & 0.004 \\
Theatre sessions per catchment & 4 & 0.002 \\
population & & \\
\hline
\end{tabular}

Using histograms, similar ranges of values for both rates of surgery and explanatory variables were demonstrated for previous years. Time series plots confirmed that the relative rankings of the districts remained largely unchanged over a 10 year period up to 1991-2.

\section{Discussion}

A greater than threefold difference in ophthalmic surgery rates was found in this study and $58 \%$ of this variation could be explained by six factors. These results are similar to those found in other specialties. ${ }^{48}$ Lewis $^{7}$ found threefold to fourfold variation in rates of herniorrhaphy, tonsillectomy, cholecystectomy, and appendectomy with, depending upon procedure, up to $70 \%$ of the variation being explained by supply variables (doctors, surgeons, and beds). Stockwell and $\mathrm{Vayda}^{8}$ found even higher variation (five to eightfold) for the five procedures they looked at with over $50 \%$ being explained by number of beds and physicians. McPherson et $a l^{4}$ found slightly less variation (up to twofold within England and Wales) but again found that at least $50 \%$ of the variation could be explained by supply variables.

In our study high throughput (indicating efficient usage of all available beds) was strongly associated with high surgical rates. This is in contrast with Sanderson ${ }^{11}$ who found no such relation between cataract extraction rates and throughput. It may be expected that districts with better availability of services would have higher rates. We found bed numbers to be strongly associated with rates and another indicator of availability; theatre sessions were also significant although staffing level indicators were not. Different combinations of these factors have also been found to be significant for other procedures. Sander$\operatorname{son}^{11}$ also found a relation between ophthalmic beds and rates and less relation with overall staffing levels. Stockwell and Vayda ${ }^{8}$ generally found bed availability to explain more variation than doctor numbers for the procedures they investigated while Lewis ${ }^{7}$ found both staffing levels and beds important to differing degrees depending on the procedure studied. BernthPetersen and Bach $^{12}$ found lower cataract extraction rates in cities without ophthalmic services when compared with cities with a service but found no direct correlation between rates and surgeon or bed supply on a county level. Given the shorter time in hospital and reduced cost associated with day case procedures, it is perhaps not surprising that high proportions of surgery being performed on a day case basis were associated with high overall rates. However, in our study, long waiting lists surprisingly appeared to be associated with high rates perhaps indicating a high need or demand for services. Goldacre et al ${ }^{15}$ expected to find that short waiting lists would be associated with high admissions from the list but if anything also found the converse.

Finally our model suggested that a high percentage of emergency admissions was associated with lower rates. This is perhaps to be expected as emergency admissions are likely to be more complicated requiring more time and longer hospital stays thus drawing resourcesfor example, theatre and bed availability, away from scheduled procedures.

Several variables found to be of importance by others were not found to be significant in our study. Some $\mathrm{e}^{14}{ }^{16}$ have found socioeconomic or ethnic characteristics to be a factor in explaining variations; however, neither underprivileged areas, as measured by the Jarman Underprivileged Area Score (calculated from eight census variables, including the proportion of elderly living alone and the proportion of unemployed ${ }^{17}{ }^{18}$ ), nor the percentage of ethnic minorities were significantly associated with rates in this model. The direction of any such effect for either factor can be argued both ways. For example, it is likely that the prevalence of certain diseases may be increased in disadvantaged groups; thus it might be expected that this variable would be associated with higher rates. Similarly, several authors have demonstrated an increased prevalence of disease, including ophthalmic diseases such as cataract ${ }^{19}$ and glaucoma, ${ }^{20}$ in some ethnic minority groups. There are several possibilities why these two variables did not appear to be significant in this study. Firstly, if there is an increased prevalence of disease in these groups then this will lead to high waiting lists, and the latter variable was indeed found to be associated with high rates of surgery. Alternatively, the lack of significance may be due to these groups not getting adequate access to care or receiving the treatment they requirethis has been demonstrated with respect to glaucoma in black Americans. ${ }^{21}$

There is, however, a significant proportion of variation not explained by our model and this may in part be due to other factors either not routinely available or more difficult to measure. Private practice rates are known to be higher in certain areas-this could compensate for perhaps lower NHS rates in these areas, 
producing apparent geographic variations when only the latter are studied. Nicholl et al ${ }^{22}$ estimated that, in $1986,16.7 \%$ of inpatients undergoing elective surgery and $10.5 \%$ of day cases in England and Wales were treated in the private sector, with large regional differences.

No information is given on the proportion of ophthalmic procedures performed privately: to obtain more detailed information on this, and its effect on the surgical cataract pool of a community, would require a separate study. Private practice rates have been found to be strongly related to social class ${ }^{23}$ so this may be a suitable surrogate measure. Socioeconomic factors were not, however, found to significantly affect rates in this study. The lack of treatment consensus for many procedures, meaning that surgeons may employ different criteria (the so called 'surgical signature' ${ }^{\text {,24 }}$ ), has been proposed as a major cause of variations. ${ }^{25}$ For example, for cataract surgery many different criteria may be used to indicate the need for surgery and even the level of visual acuity at which clinicians think surgery is indicated varies widely. ${ }^{26}$ The threshold for cataract surgery is falling owing to improving techniques. Any associated rise in surgical rate is very difficult to measure and would affect more progressive units first, thus accounting for some of the variation. It is pertinent to note also that the period covered by this study ends in early 1992 and, as mentioned, the rates of all ophthalmic surgery were not seen to vary much in the preceding years. It is also possible that case mix differences could account for some of the variation-for example, a specialist eye hospital may be expected to have a lower rate than a district general hospital as it may be undertaking more specialist, time consuming procedures. Conversely, it may be expected to have a higher rate due to better availability of services, such as increased staffing levels.

Another possibly important factor affecting rates in teaching hospitals is the training of junior doctors. The combination of time spent training plus the longer time spent by a junior doctor on each case may contribute to lower rates of surgery in these hospitals. This factor may be reflected by low throughput which was indeed found to be significantly associated with lower rates in this study. Factors such as morbidity differences and patient expectation or custom have been identified as possible causes of variation between larger areas, but are unlikely to have a large effect at a district level. Referral rates from general practices have also been shown to be associated with admission rates for certain procedures, ${ }^{27}$ although referral rates for ophthalmology were not found to vary between practices and were not associated with admission rates. With the introduction of an internal health market, factors relating to contracts may start to affect rates-for example, higher charges could lead to removal of contracts and thus lower rates, or contracts may specify minimum numbers of operations to be performed.

The use of routine data, with the possibility of data error or miscoding, has obvious drawbacks. However, as already stated, the data in this study were checked and any outliers excluded, as well as comparing with other years, so we are confident that data error and yearly fluctuations played only a small part. In addition coding differences are less likely between districts than between larger regions - for example, countries. One problem with these data is the possible discrepancy between the district of residence and district of treatment. Surgery rates and demographic data are based on district of residence but these may not relate directly to the supply variables as the district of residence may not be the district of surgery. Finally, the problem of the populations at risk not being the same as the population used in the analysis arises because some people may have already been operated on (in that year or previously) so would not be eligible for surgery. This, however, is not strictly relevant in ophthalmology because people who have had one type of operation may still be eligible for more. This still leaves the question of the independence of the data as some people may have had several operations on one or both eyes, within the year studied.

In order to rectify unnecessary variations in rates it is important to understand what causes them. This study has shown that a large proportion of variation could probably be eradicated by ensuring adequate service supply to all districts, perhaps through more equitable allocation of resources, as well as more efficient use of these resources. As day case surgery was a prominent factor in describing the variations it is important to standardise the use of day case surgery when appropriate. Although the magnitude of the effect of clinician practice styles is difficult to measure it is likely that more research into the effectiveness of procedures, coupled with the introduction of practice guidelines, such as those introduced in the UK and the USA for the management of cataract, ${ }^{28} 29$ can also help reduce unnecessary variations. The effect of private practice needs to be estimated and investigated further and data from this area need to be made more accessible.

We are grateful to Mike Davidge for his useful comments on an earlier version of this paper.

1 Pearson RJC, Smedby B, Berfenstam R, Logan RFL, Burgess AM Jr, Peterson OL. Hospital caseloads in Liverpool, New England, and Uppsala. Lancet 1968; ii: 559-66. 2 Bunker JP. Surgical manpower: a comparison of operation and surgeons in the United States and in England and Wales. N Engl f Med 1970;282:135-44.

3 Vayda E. A comparison of surgical rates in Canada and in England and Wales. N Engl f Med 1973;289:1224-9.

4 McPherson K, Strong PM, Epstein A, Jones L. Regional variations in the use of common surgical procedures: within and between England and Wales, Canada and the United States of America. Soc Sci Med 1981;15A:273-88. McPherson K, Wennberg JE, Hovind OB, Clifford P. Smallarea variations in the use of common surgical procedures: an international comparison of New England, England, and Norway. $N$ Engl $\mathcal{F}$ Med 1982;307:1310-4.

6 Glover JA. The incidence of tonsillectomy in schoo children. Proc Roy Soc Med 1938;31:1219-36.

7 Lewis CE. Variations in the incidence of surgery. $N$ Engl $f$ Med 1969;281:880-4.

8 Stockwell H, Vayda E. Variations in surgery in Ontario. Med Care 1979;17:390-6.

9 Wennberg JE, McPherson K, Caper P. Will payment based on diagnosis-related groups control hospital costs? $N$ Engl f Med 1984;311:295-300.

10 Chassin MR, Brook RH, Park RE, Keesey J, Fink A, Kosecoff J, et al. Variations in the use of medical and surgical services by the Medicare population. $N$ Engl $f$ Med $1986 ; 314: 285-90$. 
11 Sanderson HF. Regional variation in cataract extraction rates and their relationship with resource supply and need. f Roy Soc Med 1980;73:492-6.

12 Bernth-Petersen P, Bach E. Epidemiologic aspects of cataract surgery II: regional variation in frequencies. Acta Ophthalmol 1983;61:397-405.

13 Williams ES, Seward HC. Cataract surgery in South West Thames region: an analysis of age-adjusted surgery rates and length of stay by district. Public Health 1993;107:441-

14 McLaughlin CG, Normolle DP, Wolfe RA, McMahon LF Jr, Griffith JR. Small-area variation in hospital discharge rates: do socioeconomic variables matter? Med Care 1989; 27:507-21.

15 Goldacre MJ, Lee A, Don B. Waiting list statistics. I: relation between admissions from waiting list and length of waiting list. $B M F$ 1987;295:1105-8.

16 Bombardier B, Fuchs VR, Lillard LA, Warner KE Socioeconomic factors affecting the utilization of surgical operations. N Engl f Med 1977;297:699-705.

17 Jarman B. Identification of underprivileged areas. $B M F$ 1983;286:1705-9.

18 Jarman B. Underprivileged areas: validation and distribution of scores. $B M F$ 1984;289:1587-92.

19 Das BN, Thompson JR, Patel R, Rosenthal AR. The prevalence of eye disease in Leicester: a comparison of adults of Asian and European descent. $₹$ Roy Soc Med 1994;87:219Asian

Tielsch JM, Sommer A, Katz J, Royall RM, Quigley HA Javitt J. Racial variations in the prevalence of primary open- angle glaucoma: the Baltimore Eye Survey. $¥ A M A$ 1991;266:369-74.

21 Javitt JC, McBean AM, Nicholson GA, Babish JD, Warren $\mathrm{J}, \mathrm{Krakauer} \mathrm{H}$. Undertreatment of glaucoma among black Americans. N Engl f Med 1991;325:1418-22.

22 Nicholl JP, Beeby NR, Williams BT. Role of the private sector in elective surgery in England and Wales, 1986. BMF 1989;298:243-7.

$23 \mathrm{McPherson} \mathrm{K}$, Coulter A, Stratton I. Increasing use of private practice by patients in Oxford requiring common elective surgical operations. $B M \mathcal{F}$ 1985;291:797-9.

24 Wennberg J, Gittelsohn A. Variations in medical care among small areas. Sci Am 1982;246:100-11.

25 Wennberg JE. Population illness rates do not explain population hospitalization rates. Med Care 1987;25:354-9.

26 Williams MH, Frankel SJ, Nanchahal K, Coast J, Donovan JL. Cataract surgery. In: Steven A, Raftery J, eds. Health care needs assessment. Oxford: Radcliffe Medical Press, 1994; Vol 1:591-687.

27 Coulter A, Seagroatt V, McPherson K. Relation between general practices' outpatient referral rates and rates of elective admission to hospital. $B M \Im$ 1990;301:273-6.

28 The Royal College of Ophthalmologists. Guidelines for cataract surgery. Ashford, Kent: Invicta Press, 1995.

29 Cataract Management Guideline Panel. Management of cataract in adults: clinical practice guideline: quick reference guide for clinicians, number 4. Rockville, MD: US Dept of guide for clinicians, number 4. Rockville, Molth Agency for Health Care Policy and Research, 1993. 